\title{
MEMPELAJARI KESTABILAN DAN EFEK IRITASI SEDIAAN LIPSTIK YANG DIFORMULASI DENGAN LEMAK KAKAO
}

\author{
Study On Stability And Irritation Effects Of Lipstick Formulated With Cocoa Butter
}

\author{
Alfrida Lullung Sampebarra \\ Balai Besar Industri Hasil Perkebunan \\ JI.Prof .Dr. Abdurrahman Basalamah No.28 Makassar 90231 \\ Pos-el: alfridalullung@yahoo.com
}

(Artikel diterima 10 Oktober 2016; direvisi 16 November 2016; diterima 9 Desember 2016)

\begin{abstract}
A study on stability and irritation effects of lipstick, formulated with cocoa butter has been done. The basic formulas of the lipstick refer to Risnawati et al, formula (2012). In this case, the addition of cocoa butter and ceraalba in the formulation of the lipstics was varied, respectively, at $A(5,23 \%$ and $32,17 \%), B$ $(10,40 \%$ and $26,96 \%)$, and $C(15,70 \%$ and $21,74 \%)(w / w)$. The results showed that the addition of 5,23\% cocoa butter and $32,17 \%$ cera alba $(A)$, resulted in the best in the lipstick formulas, in terms of homogenity, melting point, sticking power on the lips, and color intensity. In the clinical test, it also showed not irritation efects on the skin.
\end{abstract}

Keywords: lipstick, cocoa butter, stability, skin irritation

Abstrak. Penelitian stabilitas dan efek iritasi lipstik, yang diformulasi dari lemak kakao, telah dilakukan. Formula dasar dari lipstik mengacu pada formula Risnawati et al. (2012). Dalam hal ini, penambahan lemak kakao dan ceraalba pada formulasi lipstik divariasikan, masing- masing $A(5,23 \%$ dan 32,17\%), B (10,40\% dan 26,15,7\%), dan C (15,70\% dan 21,74\%) (w/w). Hasil penelitian menunjukkan bahwa, penambahan 5,23\% lemak kakao dan 32,17\% cera alba (A) menghasilkan formula terbaik, ditinjau dari homogenitas, titik leleh, daya oles yang lebih menempel pada bibir, dan intensitas warna. Hasil uji klinis, juga menunjukkan tidak adanya efek iritasi pada kulit.

Kata kunci: lipstik, lemak kakao, stabilitas, iritasi kulit

\section{PENDAHULUAN}

Pewarna bibir merupakan sediaan kosmetika yang digunakan untuk mewarnai bibir dengan sentuhan artistik sehingga dapat meningkatkan estetika dalam tata rias wajah. Pewarna bibir terdapat dalam berbagai bentuk, seperti cairan, krayon, dan krim. Pewarna bibir dalam bentuk cairan dan krim umumnya memberikan selaput yang tidak tahan lama dan mudah terhapus dari bibir sehingga tidak begitu digemari orang, terutama jika dibandingkan dengan pewarna bibir dalam bentuk krayon. Pewarna bibir bentuk krayon lebih dikenal dengan nama lipstick (Wasitaatmadja, 1997).

Lipstick digunakan untuk memperindah bibir dengan warna yang menarik, melindungi bibir agar tidak kering, serta dapat menonjolkan sisi yang baik dan menyamarkan yang buruk pada bentuk bibir. Menurut Ani Mulyaningsih (2012), persyaratan lipstick yang baik adalah mewarnai bibir dengan rata, tidak toksik, tidak diabsorpsi oleh kulit dan tidak mengiritasi kulit, warna harus tahan di bibir tetapi juga mudah untuk dihilangkan ketika diinginkan, harus cukup keras, lembut dan mudah dioleskan pada bibir, permukaan lipstick lembut, warna homogen dan bebas partikel kasar, tidak meleleh, mengeras, pecah-pecah dalam kemasan selama penyimpanan.

Kualitas lipstik ditentukan oleh komponen penyusun basis lemak lipstick. Basis lemak lipstick merupakan formulasi dari bahan-bahan yang mempunyai titik leleh yang berbeda-beda terdiri dari malam (wax), minyak dan lemak. Bahan penyusun sediaan lipstick hendaknya berasal dari bahan alam yang lebih menguntungkan daripada bahan sintetik karena memiliki toleransi pada kulit, sehingga tidak menimbulkan iritasi yang berat terhadap bibir, Maka dari itu, perlu dicari alternatif bahan alami yang aman digunakan untuk sediaan lipstik. (Vishwakarma dkk, 2011) 
Lemak kakao selain digunakan dalam industri pangan juga digunakan dalam industri farmasi dan kosmetik. Dalam industri kosmetik lemak kakao berfungsi sebagai: (1) sumber vitamin $E$ yang mempunyai banyak manfaat untuk kulit; (2) pelembut dan melembabkan kulit; (3) penangkal radikal bebas karena mengandung tokoferol dan polifenol; (4) penunda terjadinya keriput, pelindung kulit dari polusi dan menjadikan kulit bercahaya serta awet muda (Anonim, 2012).

Lemak kakao mengandung senyawa - senyawa fungsional yang bermanfaat bagi kesehatan kulit seperti asam stearat, asam palmitat, asam oleat serta vitamin E. Asam stearat pada lemak kakao dapat berfungsi sebagai emolien yang dapat menjaga kelembaban kulit, sedang komponen lain seperti asam oleat, asam palmitat, dan vitamin $\mathrm{E}$ (tokoferol) berfungsi untuk melembutkan, menghaluskan serta antiaging.

Keistimewaan lemak kakao dalam pembuatan kosmetik adalah cepat diserap oleh kulit karena mempunyai titik leleh yang lebih rendah dari suhu tubuh manusia yaitu 30 $-35^{\circ} \mathrm{C}$. Selain itu komposisi lemak kakaojuga mendekati komposisi lemak kulit sehingga aman untuk digunakan sebagai bahan dasar pada pembuatan kosmetik dan tidak menimbulkan kesan berminyak pada kulit.

Lemak kakao juga mempunyai kemampuan untuk mencegah atau mengatasi kekeringan kulit bibir sehingga membuat bibir lebih lembut dan menarik. (Eky Restiyantyi, 2002). Tujuan penelitian adalah untuk mengetahui karakterisasi kondisioner rambut yang diformulasi dengan lemak kakao dan minyak zaitun yang dihasilkan.

\section{METODOLOGI}

\section{Bahan dan Alat}

Bahan-bahan yang akan digunakan untuk pembuatan sediaan lipstick adalah : lemak kakao, cera alba, propilen glikol, metyl paraben, propil paraben, cetyil alcohol, poli etilen glikol, minyak zaitun, oil ricini, vacelin album, BHT, dan pewarna.

Alat yang digunakan untuk pembuatan sediaan lipstick adalah timbangan analitik,
$\mathrm{pH}$ meter, termometer, waterbath, Waskom stainless steel, lumpang porcelain, botol plastik, beaker glass, gelas ukur, sendok takar, gelas pengaduk, dan lain-lain.

\section{Metode Penelitian}

Penelitian ini meliputi pembuatan formula sediaan dan pengujian karakteristik lipstick yang terdiri dari uji titik leleh, homogenitas, konsistensi, dan efek iritasi terhadap kulit. Komposisi formula dasar yang digunakan mengacu pada formula lipstick hasil penelitian Risnawati et al, ( 2012 ) yang dimodifikasi dengan Pembuatan sediaan lipstik variasi penambahan cera alba dan lemak kakao.

\section{Prosedur Pembuatan Lipstik}

Metil paraben dilarutkan dalam propilen glikol, dan zat warna digerus bersama BHT dan dilarutkan dalam oil ricini. Campuran antara metil paraben dan propilen glikol dimasukkan dalam campuran zat warna dan diaduk sampai homogen (campuran A). Cera alba, PEG, lanolin (minyak zaitun), vaselin album dan cetyl alcohol dimasukkan dalam gelas piala kemudian dilebur diatas waterbath pada suhu $65-70^{\circ} \mathrm{C}$ (campuran B). Kemudian campuran A dimasukkan ke dalam campuran B kemudian dilakukan pengadukan menggunakan mixer dalam kondisi panas (diatas waterbath). Setelah adonan tercampur rata langsung dimasukkan ke dalam cetakan lipstik.

Formula dasar lipstik adalah sebagai berikut Metyl paraben 0.1\%, Propilen glikol $5.22 \%$, BHT $0.1 \%$, Oleum ricini $7.87 \%$, Veselin $33.45 \%$, Lanolin $7.87 \%$, Cetyl alcohol $5.91 \%$, Pewarna $2.09 \%$.

Penambahan lemak kakao dan cera alba divariasikan, Lemak kakao Formula $A=5,22 \%, B=10,40 \%$ dan $C=15,70 \%$ (b/b),sedangkan cera alba adalah Formula $A=32,17 \%, B=26,96 \%$ dan $C=21,74 \%$.

\section{Parameter Uji}

Pengujian sediaan lipstik dilakukan terhadap titik leleh, homogenitas, konsistensi, dan efek iritasi terhadap kulit. 


\section{Uji Titik leleh}

Sejumlah 0,5 gram masing-masing Lipstik uji (A,B, dan C) di tempatkan dalam kaca arloji kemudian dimasukkan ke dalam oven suhu $500 \mathrm{C}$, didiamkan kemudian diamati apakah lipstik sudah mulai meleleh. setelah itu suhu dinaikkan $1^{\circ} \mathrm{C}$ dan diamati pada suhu berapa lipstik mulai meleleh.

\section{Uji Kekuatan lipstik}

Kekuatan lipstik ditentukan dengan cara meletakkan lipstik secara horisontal kemudian pada jarak kira - kira $1 / 2$ inci dari tepi lipstik digantungkan beban. Penambahan beban terus dilakukan setiap 30 detik sampai lipstik patah. Berapa beban keseluruhan sampai lipstik patah di kategorikan sebagai kekuatan lipstik.

\section{Uji Daya Oles}

Daya oles ditentukan dengan cara mengoleskan lipstik pada lengan sebanyak 10 kali kemudian diamati warna lipstick yang menempel pada lengan. Sediaan lipstik dikatakan mempunyai daya oles jika warna yang menempel pada kulit lengan banyak dan merata.

\section{Uji Homogenitas}

Uji homogenitas ke 3 tipe lipstik dilakukan dengan menempatkan sejumlah 0,5 gram masing - masing lipstick ke atas permukaan kaca objek kemudian diratakan dengan menggunakan kaca obyek yang lainnya dengan tekanan tertentu.

\section{Uji Iritasi Kulit}

Kelinci yang digunakan adalah kelinci albino, galur New Zealand sebanyak 3 (tiga) ekor dengan bobot tiap kelinci $>2 \mathrm{~kg}$ (sesuai panduan WHO) (Ritten and Franklin, 1990) bahwa kelinci yang digunakan diaklimatisasi terlebih dahulu selama 3 hari. Satu hari sebelum percobaan, punggung kelinci dibersihkan dari bulu dengan mencukur. Selanjutnya disiapkan dua daerah uji pada punggung kelinci yang telah bersih dari bulu, masing-masing pada sisi kanan dan kiri. Pada masing-masing daerah uji dioleskan sebanyak $500 \mathrm{mg}$ sediaan. Selanjutnya daerah uji ditutup dengan kaca hipoalergik, kertas selofan kemudian diperban dengan perban elastis. Kelinci dibiarkan dalam keadaan diperban selama pengamatan. Pengamatan dilakukan pada waktu 24, 48, dan 72 jam setelah pemberian sediaan (sesuai panduan pengujian WHO dan ISO 10993.10). Parameter yang diamati adalah eritema, eskar dan udem serta efek-efek lain (Hayes, 2001). Jika terjadi eritema, eskar dan udem pada mata kelinci, maka diberi skor sesuai panduan pengujian. Berdasarkan skor eritema, eskar dan udem selanjutnya dihitung Indeks Iritasi Kutan Primer (IIKP).

Untuk pengamatan sesuai panduan pengujian (WHO dan ISO 10998.10), masingmasing kelinci diolesi dengan $500 \mathrm{mg}$ sediaan contoh uji pada kulit kelinci dan diamati pada 0 jam; $T_{24}$ (24 jam); $T_{48}$ (48 jam); $T_{72}$ (72 jam) setelah pemberian sediaan kondisioner rambut. Bila pada 24 jam tidak terjadi iritasi kulit maka pengamatan dilanjutkan sampai 48 jam begitupun selanjutnya sampai 72 jam.

Efek iritasi sediaan kondisioner pada kulit digunakan skor penilaian berdasarkan pedoman skor iritasi OECD dan Draize (Hayes, 2001). Indeks iritasi primer adalah sebagai berikut : antara 0 sampai 1 hampir tidak mengiritasi, 1 sampai 2 menunjukkan iritasi ringan, 2 sampai 5 menunjukkan iritasi sedang, dan di atas 5 menunjukkan iritasi berat.

Nilai IIKP diperoleh dengan menjumlahkan nilai eritema dan edema. Perhitungan indeks iritasi primer dilakukan dengan menghitung rata-rata skor eritema dari ketiga kelinci kemudian dilakukan ratarata dari pengamatan 24 hingga 72 jam. Hasil rata-rata terakhir merupakan nilai indeks iritasi primer.

\section{HASIL DAN PEMBAHASAN}

Hasil analisis titik leleh, kekuatan dan iritasi sediaan lipstik dapat dilihat pada Tabel 1. 
Tabel 1. Hasil analisis titik leleh, kekuatan, dan iritasi sediaan lipstick

\begin{tabular}{cccc}
\hline Formula & $\begin{array}{c}\text { Titik } \\
\text { leleh }\left({ }^{\circ} \mathbf{C}\right)\end{array}$ & $\begin{array}{c}\text { Kekuatan } \\
(\mathbf{g})\end{array}$ & $\begin{array}{c}\text { Iritasi } \\
\text { kulit IIKP }\end{array}$ \\
\hline $\mathrm{A}$ & 58 & 215 & 0.42 \\
$\mathrm{~B}$ & 54 & 215 & 0.42 \\
$\mathrm{C}$ & 54 & 165 & 0.42 \\
\hline
\end{tabular}

\section{Titik Leleh}

Dari Tabel 1 menunjukkan bahwa sediaan lipstik dari ke tiga formula $A, B$ dan C memiliki kisaran titik leleh antra 54 - 58 - C. lipstik A mempunyai titik leleh yang lebih tinggi dibanding lipstik $B$ dan $C$. Hal ini disebabkan karena konsentrasi cera alba yang ditambahkan ke dalam adonan lipstik formula A lebih tinggi dibanding yang lainnya. Diketahui bahwa Cera alba mempunyai titik leleh yang tinggi yaitu $62-65{ }^{\circ} \mathrm{C}$ sehingga dapat meningkatkan titik leleh lipstik, sedangkan lemak kakao mempunyai titik leleh yang rendah yaitu 35 $40^{\circ} \mathrm{C}$ (Rowe, et al., 2009). Berdasarkan nilai titik leleh tersebut menunjukkan bahwa ke tiga formula lipstik yang dibuat memiliki titik lebur yang baik dan memenuhi syarat SNI 16-4769-1998 yaitu titik lebur adalah $50^{\circ}$ $70{ }^{\circ} \mathrm{C}$. Menurut Vishwakarma, et al, (2011) bahwa lipstik yang baik memiliki titik lebur di atas $50^{\circ} \mathrm{C}$.

\section{Kekuatan Lipstik}

Pada Tabel 1 menunjukkan bahwa sediaan lipstik formula A, B dan C memiliki kisaran kekuatan antara $165-215 \mathrm{~g}$. Sediaan lipstik formula A dan B mempunyai kekuatan yang sama yaitu masing-masing $215 \mathrm{~g}$ sedangkan lipstik formula C $165 \mathrm{~g}$. Adanya perbedaan nilai kekuatan sediaan lipstik tersebut kemungkinan disebabkan oleh perbandingan konsentrasi lemak kakao dan cera alba yang ditambahkan ke dalam adonan lipstik. Penambahan cera alba pada konsentrasi $21,74 \%-32,17 \%$, dan lemak kakao 5,22 \%, - 15,70 \% menghasilkan nilai kekuatan lipstik yang sama yaitu masing-masing $215 \mathrm{~g}$ (formula $\mathrm{A}$ dan $\mathrm{B}$ ) tetapi mempunyai titik leleh yang berbeda namun kedua sediaan lipstik tersebut masih memenuhi syarat SNI lipstik.

Berdasarkan hasil uji kekuatan, ketiga formula lipstik yang dihasilkan dalam penelitian ini memiliki kekuatan yang baik. Kesimpulan ini diambil dengan membandingkan berat beban yang digunakan pada pengujian sediaan lipstik menggunakan lemak kakao dengan dua sediaan lipstik yang beredar di pasaran, dimana lipstik pembanding yang digunakan patah pada penekanan dengan penambahan berat 84,97 gram dan 94,97 gram. Evaluasi kekerasan lipstik menunjukkan kualitas patahan lipstik dan juga kekuatan lipstik dalam proses pengemasan, pengangkutan, dan penyimpanan. (Risnawati 2012 ).

Nampaknya bahwa semakin banyak lemak kakao yang ditambahkan ke dalam formula, sediaan lipstik semakin mudah patah sebaliknya semakin banyak cera alba yang digunakan maka akan membuat lipstik semakin kuat. Konsentrasi cera alba yang ditambahkan dapat meningkatkan jumlah padatan dalam emulsi sehingga sediaan lipstik yang terbentuk akan semakin keras sebaliknya penambahan lemak akan menambah jumlah cairan dalam emulsi sehingga sediaan lipstik yang terbentuk akan semakin lunak dan nampak creamy serta mudah patah. Cera alba membuat lipstik agar selalu dalam bentuk padat walaupun iklim panas. (Uni Unirah, 2011).

\section{Efek Iritasi Kulit}

Pengujian keamanan sediaan lipstik dievaluasi dengan uji iritasi pada kulit punggung kelinci. Untuk menilai efek iritasi suatu sediaan atau kosmetik pada kulit digunakan skor penilaian berdasarkan pedoman skor iritasi OECD dan Draize (Hayes, 2001). Hasil pengamatan uji iritasi pada kulit punggung kelinci ditunjukkan pada Tabel 2. 
Tabel 2. Hasil Pengujian Efek Iriitasi Pada Kulit

\begin{tabular}{|c|c|c|c|c|c|c|c|c|c|c|c|c|c|c|}
\hline \multirow{3}{*}{ Formula } & \multirow{3}{*}{$\begin{array}{c}\text { Periode } \\
\text { Pengujian } \\
\text { (jam) }\end{array}$} & \multicolumn{4}{|c|}{ Kelinci 1} & \multicolumn{4}{|c|}{ Kelinci 2} & \multicolumn{4}{|c|}{ Kelinci 3} & \multirow{3}{*}{ IIKP } \\
\hline & & \multirow{2}{*}{$\begin{array}{l}\text { Kiri } \\
E\end{array}$} & \multicolumn{3}{|c|}{ Kanan } & \multirow{2}{*}{$\frac{\text { Kiri }}{\mathrm{E}}$} & \multicolumn{3}{|c|}{ Kanan } & \multicolumn{2}{|c|}{ Kiri } & \multicolumn{2}{|c|}{ Kanan } & \\
\hline & & & $\mathbf{U}$ & $E$ & U & & $\mathbf{U}$ & $E$ & $\mathbf{U}$ & $E$ & U & $E$ & $\mathbf{U}$ & \\
\hline \multirow{3}{*}{ A } & 24 & 1 & 0 & 1 & 0 & 1 & 0 & 1 & 0 & 1 & 0 & 1 & 0 & \multirow{3}{*}{0.42} \\
\hline & 48 & 1 & 0 & 1 & 0 & 1 & 0 & 1 & 0 & 1 & 0 & 1 & 0 & \\
\hline & 72 & 0,5 & 0 & 0,5 & 0 & 0,5 & 0 & 0,5 & 0 & 0,5 & 0 & 0,5 & 0 & \\
\hline \multirow{3}{*}{ B } & 24 & 1 & 0 & 1 & 0 & 2 & 0 & 1 & 0 & 1 & 0 & 1 & 0 & \multirow{3}{*}{0.42} \\
\hline & 48 & 1 & 0 & 1 & 0 & 1 & 0 & 1 & 0 & 1 & 0 & 1 & 0 & \\
\hline & 72 & 0,5 & 0 & 0,5 & 0 & 0,5 & 0 & 0,5 & 0 & 0,5 & 0 & 0,5 & 0 & \\
\hline \multirow{3}{*}{ C } & 24 & 1 & 0 & 1 & 0 & 1 & 0 & 1 & 0 & 1 & 0 & 1 & 0 & \multirow{3}{*}{0.42} \\
\hline & 48 & 1 & 0 & 1 & 0 & 1 & 0 & 1 & 0 & 1 & 0 & 1 & 0 & \\
\hline & 72 & 0,5 & 0 & 0,5 & 0 & 0,5 & 0 & 0,5 & 0 & 0,5 & 0 & 0,5 & 0 & \\
\hline
\end{tabular}

Indeks iritasi kulit primer $=0$

Keterangan : $\mathrm{E}=$ Eritema, $\mathrm{U}=\mathrm{Udem}$

Berdasarkan hasil uji iritasi menunjukkan bahwa pada pengamatan 24 , 48 hingga 72 jam, hanya muncul efek eritemaeskar (reaksi kemerahan) yang berangsur - angsur hilang dan tidak menimbulkan efek Udem (bengkak). Nilai indeks iritasi primer diperoleh dengan menjumlahkan nilai eritema dan edema. Perhitungan indeks iritasi primer dilakukan dengan menghitung rata-rata skor eritema dari ketiga kelinci kemudian dilakukan rata -rata dari pengamatan 24 dan 72 jam. Hasil rata-rata terakhir merupakan nilai indeks iritasi primer. Nilai indeks iritasi primer untuk ketiga lipstik $A, B$ dan $C$ adalah sebesar 0,42. nilai indeks iritasi Kulit Primer (IIKP) yang ditunjukkan pada ketiga formula lipstick tersebut dapat dikatakan tidak bersifat mengiritasi kulit. Hal ini disebabkan karena konsentrasi masing-masing senyawa yang digunakan pada formula masih berada pada rentang yang ditoleransi sehingga tidak berpengaruh terhadap munculnya reaksi iritasi. Berdasarkan persyaratan $\mathrm{WHO}$ ke tiga lipstik tersebut tidak bersifat mengiritasi kulit (IIKP < 0.5).

\section{UJI DAYA OLES}

Tabel 3. Hasil analisa daya oles pada berbagai formula lipstik

\begin{tabular}{ccccc}
\hline \multicolumn{4}{c}{ Parameter } \\
\hline $\begin{array}{c}\text { For } \\
\text { mula }\end{array}$ & $\begin{array}{c}\text { Homo } \\
\text { genitas }\end{array}$ & Tekstur & Kilap & $\begin{array}{c}\text { Daya } \\
\text { oles }\end{array}$ \\
\hline A & 3.0 & 2.0 & 2.0 & 2.0 \\
B & 3.0 & 2.0 & 2.6 & 4.0 \\
C & 3.0 & 2.0 & 4.0 & 3.0 \\
\hline
\end{tabular}

Ket :

\begin{tabular}{|c|c|c|}
\hline $\begin{array}{l}\text { Homogenitas } \\
1: \text { Tidak homogen } \\
2: \text { Agak homogen } \\
3: \text { Homogen } \\
4: \text { Sangat homogen } \\
5: \text { Sangat homogen sekali }\end{array}$ & $\begin{array}{l}\text { Tekstur } \\
1: \text { Halus } \\
2: \text { Agak halus } \\
3: \text { Agak kasar } \\
4: \text { Kasar } \\
5: \text { Kasar sekaliu }\end{array}$ & $\begin{array}{l}\text { Kilap } \\
1: \text { Kilap } \\
2: \text { Agak Kilap } \\
3: \text { Agak pudar } \\
4: \text { Agak kusam } \\
5: \text { Kusam }\end{array}$ \\
\hline $\begin{array}{l}\text { Daya oles } \\
1: \text { Sangat menempel } \\
2: \text { Menempel } \\
3: \text { Agak menempel } \\
4: \text { Agak tidak menempek } \\
5: \text { Tidak menempel }\end{array}$ & $\begin{array}{l}\text { Aroma } \\
1: \text { Tidak berbau } \\
2: \text { Agak sedikit berbau } \\
3: \text { Agak berbau } \\
4: \text { Agak harum } \\
5: \text { Harum }\end{array}$ & \\
\hline
\end{tabular}

\section{Daya Oles}

Sediaan lipstik dikatakan mempunyai daya oles yang baik jika warna yang menempel pada kulit punggung tangan banyak dan merata dengan beberapa kali pengolesan. Sedangkan sediaan dikatakan mempunyai daya oles yang tidak baik jika warna yang menempel sedikit dan tidak merata (Keithler, 1956) 
Tabel 3 menunjukkan bahwa sediaan lipstik formula $A$ dengan konsentrasi lemak kakao 5, $22 \%$ menempel sekali pada bibir. Lipstik dengan konsentrasi lemak kakao $10,40 \%$ dan tidak menempel pada bibir (3.0) sedangkan Lipstik dengan konsentrasi lemak kakao 15,70 \% tidak menempel (4.0). Lipstik cenderung semakin tidak menempel dengan meningkatnya konsentrasi lemak kakao. penambahan konsentrasi lemak kakao menyebabkan jumlah cairan lebih banyak dalam emulsi sehingga sediaan yang dihasilkan menjadi tidak homogen dan merata, dan lebih lunak sehingga tidak bisa dioleskan pada bibir. Daya oles lipstik dipengaruhi oleh konsentrasi cera alba dan lemak di dalam campuran. Semakin keras suatu lipstik atau semakin lunak daya olesnya semakin rendah. (Oscar Perdanakusuma, 2003).

\section{Homogenitas}

Uji homogenitas dilakukan dengan menempatkan sejumlah lipstik keatas permukaan kaca obyek kemudian diratakan dengan menggunakan kaca obyek yang lainnya dengan tekanan tertentu untuk mengetahui suatu sediaan tercampur merata antara bahan aktif dan bahan tambahan pada kaca preparat. Hasil pemeriksaan homogenitas ke tiga formula $\mathrm{A}, \mathrm{B}$ dan $\mathrm{C}$ menunjukkan bahwa seluruh sediaan lipstick tidak memperlihatkan adanya butir-butir kasar pada saat sediaan dioleskan pada kaca objek. Hasil uji homogenitas ke tiga formula mendapat nilai skor masing-masing 3.0 (homogen) Hal ini menunjukkan bahwa sediaan yang dibuat mempunyai susunan yang homogen (Ditjen POM, 1979).

\section{Kilap}

Tabel 3 menunjukkan bahwa lipstick dengan konsentrasi lemak kakao 5.22 $\%$ dan $\quad 10.40 \%$ mempunyai kilap yang mengkilap ( 2.0 dan 2,6 ) sedangkan lipstik dengan konsentrasi lemak kakao $15.70 \%$ agak kusam (4.0) yang berarti bahwa pada konsentrasi tersebut lipstick tidak menempel dan tidak homogen. Semakin rendah nilai kilap lipstik berarti semakin menempel dan homogen. Kilap berhubungan erat dengan konsentrasi cera alba yakni semakin meningkat konsentrasi malam lipsticknya semakin kusam.

\section{Tekstur}

Dari Tabel 3 menunjukkan bahwa tekstur lipstik ke tiga formula mempunyai nilai yang sama yaitu masing-masing 2 (dua) yang berarti ke tiga formula lipstik tersebut mempunyai tekstur agak halus. Semakin tinggi nilai tekstur lipstik semakin kasar.

\section{UJI ORGANOLEPTIK}

Tabel 4 . Rekapitulasi nilai organoleptik pada berbagai kriteria mutu pada berbagai formula lipstik

\begin{tabular}{|c|c|c|c|c|c|c|}
\hline \multirow{3}{*}{ formula } & \multicolumn{6}{|c|}{ Lama Penyimpanan } \\
\hline & \multicolumn{3}{|c|}{ Sebelum penyimpanan } & \multicolumn{3}{|c|}{ Setelah penyimpanan 2 bulan } \\
\hline & Warna & Aroma & Penampakan & Warna & Aroma & Penampakan \\
\hline A & Merah & $\begin{array}{l}\text { Tidak } \\
\text { berbau }\end{array}$ & Padat lembek & merah & $\begin{array}{l}\text { Tidak } \\
\text { berbau }\end{array}$ & $\begin{array}{l}\text { Padat lembek, } \\
\text { tidak pecah, tidak } \\
\text { kering }\end{array}$ \\
\hline B & Merah & $\begin{array}{l}\text { Tidak } \\
\text { berbau }\end{array}$ & Padat lembek & merah & $\begin{array}{l}\text { Tidak } \\
\text { berbau }\end{array}$ & $\begin{array}{l}\text { Padat lembek, } \\
\text { tidak pecah, tidak } \\
\text { kering }\end{array}$ \\
\hline $\mathrm{C}$ & merah & $\begin{array}{l}\text { Tidak } \\
\text { berbau }\end{array}$ & Padat lembek & merah & $\begin{array}{l}\text { Tidak } \\
\text { berbau }\end{array}$ & $\begin{array}{l}\text { Padat lembek, } \\
\text { tidak pecah, tidak } \\
\text { kering }\end{array}$ \\
\hline
\end{tabular}


Dari Tabel 4. menunjukkan bahwa sebelum dan setelah penyimpanan lipstick selama dua bulan pada suhu ruang, ternyata semua parameter (aroma, warna dan penampakan) yang diamati tidak mengalami perubahan.

\section{SIMPULAN}

Dari hasil dan pembahasan dapat disimpulkan bahwa formulas lipstik berbahan dasar lemak kakao dengan penggunaan lemak kakao masing - masing $5,22 \%$ dan cera alba $32.17 \%$ dapat menghasilkan Formula lipstik yang lebih homogen, mempunyai titik leleh paling tinggi, daya olesnya kebih menempel, warna lebih intensif, dan hasil uji klinis terhadap kulit tidak bersifat iritasi.

\section{DAFTAR PUSTAKA}

1. BPOM, 2004. "Peraturan Perundangundangan di Bidang Kosmetik "Balai POM RI, Jakarta.

2. BSN, 1996. SNI 16-4399-1996: Pelembab Kulit

3. Balsam, M.S. (1972). Cosmetic Science and Technology edisi kedua. London: John Willy and Son, Inc. Halaman 64.

4. Fatmawati, A, Ermina Pakki, dan Michrun Nisa.. 2012. Sains dan Teknologi Kosmetik, Makassar.

5. Hayes, A.W., 2001. Principles and Methods of Toxicology, $4^{\text {th }}$. Philadelphia: Taylor and Francis.

6. Hasni Hasan, N. 2008. Pembuatan Alas Bedak Rose (Tidak Dipublikasikan). Laboratorium Terpadu Program Profesi Apoteker. Fakultas Farmasi Unhas, Makassar

7. ISO 10993-10-1995. Biological Evaluation of Medical Devices-Part 10; Test Geneva, 1995, 2-5.
8. Keithler, W.R. 1956. The Formulation of Cosmetics and Cosmetic Specialities. Drug and Cosmetic Industry, New York.

9. Klokke, A.H, 1980. Pedoman Untuk Pengobatan Luar Penyakit Kulit. Gramedia, Jakarta.

10. Ritter, L. and C.A., Franklin, 1990. Dermal Toxicity Testing; Exposure and Absorption, in Handbook of Invivo Toxicity Testing D. L. Arnold, H.C. Grice, and D.R. Krewski (Eds.,). Toronto: Academic Press.

11. Schmitt WH. 1996. Skin Care Product. Didalam Williams DF dan Schmitt WH, editor. Chemistry and Technology of The Cosmetics and Toiletries Industry. $2^{\text {nd }}$ Ed. London: Blackie A Cademe and Profesional

12. Wilkinson 7B, Moore R7. 1983. Harry's Cosmeticology, London.

13. Risnawati, Nazliniwaty*, dan Djendakita Purba, Departemen Teknologi Farmasi Fakultas Farmasi Universitas Sumatera Utara, Medan, Indonesia Journal of Pharmaceutics and Pharmacology, 2012 Vol. 1 (1): $78-86$

14. Rowe, C.R., Paul, J., dan Marian, E.Q.(2009). Handbook of Pharmaceutical Excipients. Edisi keenam. Washington: Pharmeceutical Press. Halaman: 772.

15. Vishwakarma, B., Dwivedi, S., Dubey, K., dan Joshi, H. (2011).

16. Oscar Perdanakusuma dan Zakiah Wulandari, Optimasi Proses Pembuatan Lipstik Dengan Penambahan Berbagai Konsentrasi Malam Lebah Program Studi Teknologi Hasil Ternak, Departemen IImu Produksi Ternak, Fakultas Peternakan, IPB

17. Wasitaatmadja, S.M. (1997). Penuntun IImu Kosmetik Medik. Jakarta: UI-Press. Halaman 28. 